\title{
DEPENDENCE OF STORAGE MATERIAL SURFACES ON THE OXIDATIVE RANCIDITY KINETICS OF PEANUT OIL
}

\section{Chidi Edbert Duru ${ }^{1, a^{*}}$, ljeoma Akunna Duru, ${ }^{2, b}$, Chike Anthony Nweze ${ }^{2, c}$ and Lugard Ukiwe ${ }^{2, d}$}

\author{
1Department of Chemistry, Imo State University, Owerri, P.M.B. 2000, Owerri Imo State, Nigeria. \\ ${ }^{2}$ Department of Chemistry, Federal University, Owerri, P.M.B.1526, Owerri Imo State, Nigeria. \\ a chidiedbertduru@gmail.com, b akunnaobiji@yahoo.com , cchykememore@gmail.com \\ duggil2002@yahoo.com
}

Keywords: Oxidative rancidity, Surfaces, Peanut oil, Passivity, Aluminum, Plastic

\begin{abstract}
The rates of oxidative rancidity of peanut oil in contact with iron, copper, zinc, aluminum, tin, polyethylene (PE), glass and magnesium were studied. The rancidity of the oil in the surfaces made of these materials decreased in the order $\mathrm{Mg}>\mathrm{Fe}>\mathrm{Cu}>\mathrm{Sn}>\mathrm{Glass}>\mathrm{Zn}>\mathrm{Al}>\mathrm{PE}$. The order obtained showed that the rancidity process does not depend on the activity of these surfaces, but has a possible link with surface passivity. The values for the rate of rancidity in $\mathrm{Mg}$ and $\mathrm{Fe}$ surfaces where the process was fastest were $2.08 \times 10^{-5}$ and $1.39 \times 10^{-5} \mathrm{mmolkg}^{-1} \mathrm{hr}^{-1}$ respectively, while values for the lowest rates of rancidity obtained for $\mathrm{Al}$ and $\mathrm{PE}$ surfaces were $2.78 \times 10^{-6}$ and $1.07 \times$ $10^{-6} \mathrm{mmolkg}^{-1} \mathrm{hr}^{-1}$ respectively. The use of aluminum and PE vessels for the storage of peanut oil would increase its shelf-life by keeping the oil in its original state for a longer period of time.
\end{abstract}

\section{Introduction}

Peanut oil also known as groundnut oil or arachis oil is a vegetable oil derived from peanuts. Its major components of fatty acids are oleic acid (46.8\%), linoleic acid (33.4\%) and palmitic acid $(10.0 \%)$. The fat content of the oil put together gives about $32 \%$ of polyunsaturated fatty acids [1]. Oxidative rancidity of fats and oils refers to the undesirable odours and flavors which develop when fatty acids or its products are exposed to the oxygen in the air [2]. The most susceptible fatty acids to oxidation rancidity are those oils which are rich in polyunsaturated fatty acids [3]. The polyunsaturated fatty acid portions of these foods react with oxygen to form peroxides. The peroxides decompose to yield mixtures of aldehydes, ketones, and other volatile products [4]. These products are responsible for the rancid odour and flavours. Highly saturated products, such as butter, are not as prone to oxidative rancidity due to the absence of polyunsaturated fatty acid compounds.

Oxidative rancidity results from more complex lipid oxidation processes. The processes are generally considered to occur in three phases: an initiation or induction phase, a propagation phase and a termination phase. In complex systems, the products of each of these phases will increase and decrease over time, making it difficult to quantitatively measure lipid oxidation $[2,5,6]$. During the process, hydrogen abstraction from unsaturated fatty acids becomes selective for the most weakly bound hydrogen. The ease of hydroperoxidation depends on the number of double bonds present [6]. 


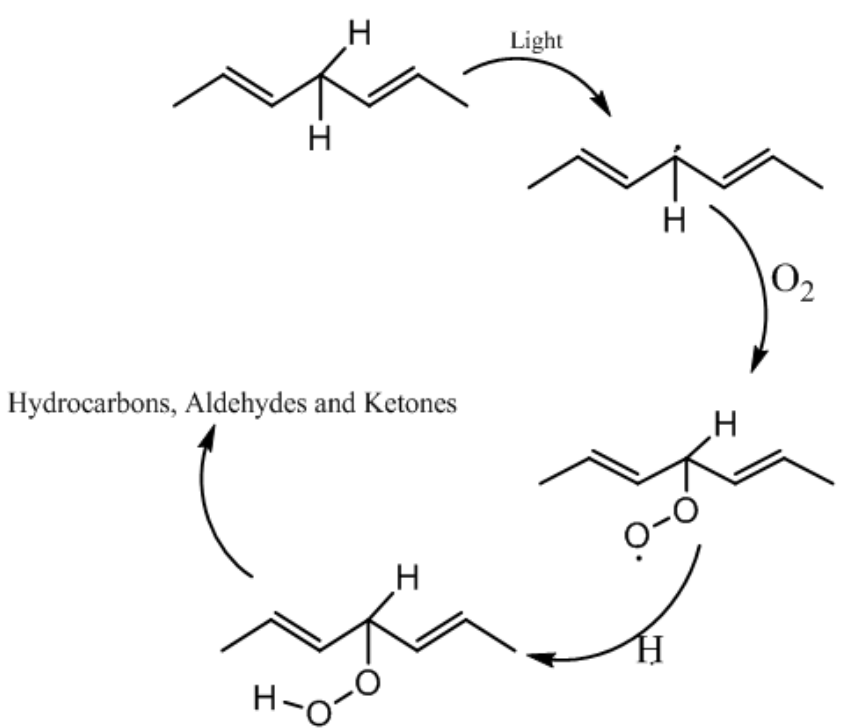

Figure 1: Mechanism of oxidative rancidity of poly-unsaturated oils

Heat and light also increase the rate of this process and other phases of lipid oxidation $[7,8,9]$. In the final termination phase of lipid oxidation, relatively unreactive compounds are formed including hydrocarbons, aldehydes and ketones.

Metals such as copper, iron, manganese and chromium increase rate of fat oxidation. As a result, the preferred storage containers are steel drums, tin or nonmetallic materials such as plastic $[10,11,12,13,14,15]$. Stainless steel is commonly used in processing plants so as to avoid excessive contact with metals that increase fat oxidation. Water with trace metal is also a cause of rancidity in food products [16].

The present study would measure the contribution of different material surfaces on the oxidative rancidity of peanut oil. The effect of these surfaces on the rate of oxidative rancidity would also be determined.

\section{Materials and Method}

\section{Sample collection}

Fresh peanut seeds were bought from Ekeukwu Owerri market in Imo State. The seeds were washed, dried for 2 hours and pulverized in an electric blender. The resultant slurry was then transferred into a glass jar and corked.

\section{Oil extraction}

The seed slurry was subjected to cold extraction with n-hexane. $500 \mathrm{ml}$ of the solvent was transferred into the jar and the cork replaced. The jar was gently swirled at 10 minutes interval for 1 hour. The mixture was then filtered with a white cotton cloth into a beaker. The slurry residue was then washed thrice using fresh solvent. The extract was refilter with filter paper before it was poured into the round bottom flask of a rotary evaporator for solvent removal. The extracted oil was dried using 1 gram of anhydrous sodium sulphate.

\section{Effect of surfaces on rate of rancidity}

The effect of different surfaces on the rate of rancidity of the freshly extracted oil was determined using iron, copper, zinc, aluminum, tin, polyethylene (PE), glass containers and a polyethylene beaker with pieces of magnesium ribbons. All the vessels used were cylindrical, $50 \mathrm{~mm}$ in height with the iron, copper, zinc, aluminum, tin and magnesium vessels having a thickness of $1.0 \mathrm{~mm}$ while the polyethylene was $2.0 \mathrm{~mm}$ thick. $30 \mathrm{ml}$ of the freshly extracted peanut oil was transferred into the containers. The containers were left to stand on a bench with equal exposure to air and light. Oil from each container was weighed out and determined for peroxide value using AOAC method [17]. Oil sample ( $2 \mathrm{~g})$ was dissolved in $30 \mathrm{ml}$ of chloroform: acetic acid $(3: 2, \mathrm{v} / \mathrm{v})$ then $1 \mathrm{ml}$ freshly prepared saturated KI (potassium iodide) solution was added and the mixture was swirled 
for 1 minute. About $30 \mathrm{ml}$ distilled water and $0.5 \mathrm{ml}$ starch solution were added and the liberated iodine was titrated with sodium thiosulphate $(0.1 \mathrm{M})$. Peroxide value in the unit $\mathrm{mmol} / \mathrm{kg}$ was determined by the following equation:

$$
\text { Peroxide Value }(\mathrm{mmol} / \mathrm{kg})=\frac{(\mathrm{S}-\mathrm{B}) \times \mathrm{M} \times 1000}{\mathrm{~g}}
$$

$\mathrm{S}=$ volume of $\mathrm{Na}_{2} \mathrm{~S}_{2} \mathrm{O}_{3}$ at end point in sample, $\mathrm{B}=$ volume of $\mathrm{Na}_{2} \mathrm{~S}_{2} \mathrm{O}_{3}$ at end point in blank, molarity of $\mathrm{Na}_{2} \mathrm{~S}_{2} \mathrm{O}_{3}$ and $\mathrm{g}=$ weight of oil sample.

The values were determined in triplicates at ten days intervals over a period of sixty days.

\section{Results and Discussion}

The change in peroxide value of the peanut oil in the different storage materials as a function of time is shown in figure 2.

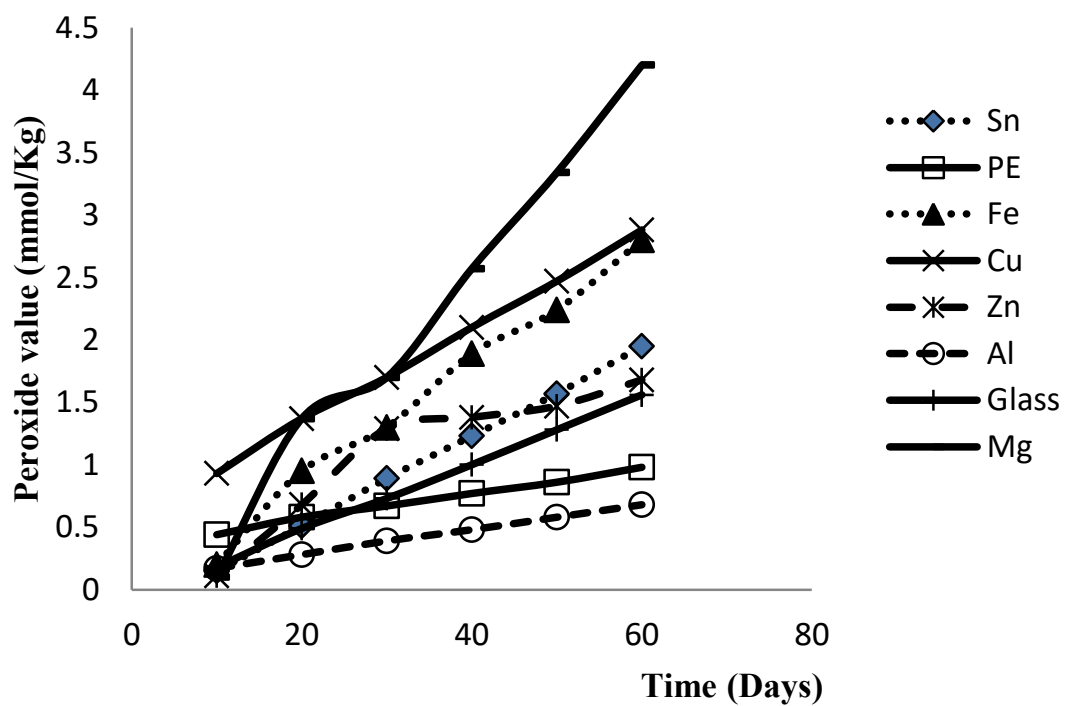

Figure 2: Plot of change in peroxide value of peanut oil as a function of time

It was evident that the peroxidation process in all the surfaces had a high dependence on the contact time. The degree of peroxidation in the study surfaces was found to increase in the order $\mathrm{Al}<\mathrm{Zn}<\mathrm{Sn}<\mathrm{Cu}<\mathrm{Fe}<\mathrm{Mg}$. Arranging the metals used for this study in the order of increasing activity, i.e. $\mathrm{Cu}<\mathrm{Sn}<\mathrm{Fe}<\mathrm{Zn}<\mathrm{Al}<\mathrm{Mg}$ shows that the degree of oxidative rancidity is not dependent on the activity of the metal surface in contact with the oil. This could be seen from the fact that glass which is not a metal gave higher peroxide value than very active metals like zinc and aluminum. Worthy of note though, is that the most active surface magnesium and the least active PE gave the highest and lowest peroxide contents in the oils respectively. The contribution of these surfaces to peroxidation can therefore be attributed to other surface properties not dependent on the oxidation states of the metals.

It has been reported that in the presence of transition metal ions, $\mathrm{ROOH}$ can give rise to the generation of radicals capable of re-initiating lipid peroxidation by redox-cycling of the metal ions [18]. Reduced $\mathrm{Fe}^{2+}$ complexes react with lipid peroxides ( $\mathrm{RCOOH}$ ) to give alkoxy radicals, whereas oxidized $\mathrm{Fe}^{3+}$ complexes react more slowly to produce peroxyl radicals. Both radicals can take part in the propagation of the chain reaction. This radical generation property of Fe could be a reason for the high peroxide value of oil stored in it.

The rate of the oxidative rancidity of peanut oil in the different storage materials is shown in table 1 and compared in figure 3. 
Table 1: Rate of oxidative rancidity of peanut oil in different storage materials

\begin{tabular}{|lcccccccc|}
\hline $\begin{array}{l}\text { Storage } \\
\text { material }\end{array}$ & $\mathrm{Sn}$ & $\mathrm{PE}$ & $\mathrm{Fe}$ & $\mathrm{Cu}$ & $\mathrm{Zn}$ & $\mathrm{Al}$ & Glass & $\mathrm{Mg}$ \\
\hline $\begin{array}{l}\text { Rate of } \\
\text { rancidity } \\
\text { (mmol/Kghr) }\end{array}$ & $8.47 \times 10^{-6}$ & $1.07 \times 10^{-6}$ & $1.39 \times 10^{-5}$ & $1.04 \times 10^{-5}$ & $5.28 \times 10^{-6}$ & $2.78 \times 10^{-6}$ & $6.94 \times 10^{-6}$ & $2.08 \times 10^{-5}$ \\
\hline
\end{tabular}

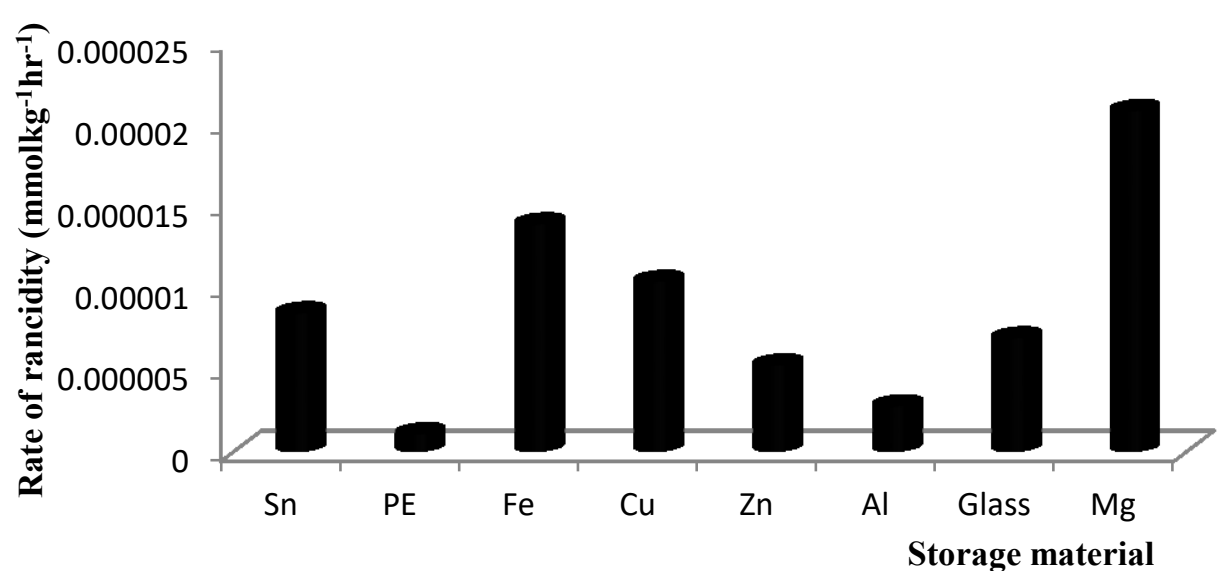

Figure 3: Rate comparison of oil rancidity in different storage materials

Rate of peroxidation was lowest in the PE material followed by aluminum. The inertness and resistance to corrosion of both surfaces can be a likely factor for the observation. Tinplate containers have been used for a longtime for oil packaging because of their many advantages which includes total protection from light, oxygen, water vapour and microorganisms, and resistance to several types of mechanical abuses. Most importantly is that the inside of the metal is protected with food approved special enamels (lacquers) that protect the metal from the corrosiveness of the product [19]. It is therefore surprising that the tin surface used in this work gave a peroxide value eight times high than the plastic surface another common present day packaging material. A possible explanation for this observation can be drawn from the work of Grover [14]. He studied the shelf life of several vegetable oils when stored in new and reused tinplate containers. The quality of oil stored in new containers did not change within one year while the oil stored in containers reused several times remained intact for only 4-5 months. The reuse of containers increases the corrosion of the tin coating and the exposed steel base readily reacts with free fatty acids in the oil leading to oxidative rancidity and organic tin-salts with high toxicity [19]. The mechanical abrasion resulting from washing and preparation of the tin-coated steel surface of the material used for this study could account for the observed high peroxide value of oil in this material.

\section{Conclusion}

The oxidative rancidity of peanut oil proceeds at different rates in all the surfaces that were studied. All the metal surfaces enhanced the rancidity process with aluminum showing the least conversion rate. The rate of oil rancidity was slowest in the PE surface. The molecular composition of this material which is devoid of oxygen-containing functional groups and electron withdrawing sites that can facilitate hydrogen abstraction from the oil molecule and breaking of the double bond in oxygen molecule for the peroxidation process might be responsible for the observed slow rate. For better shelf life of peanut oil therefore, aluminum and PE containers are best suited for its storage. 


\section{References}

[1] K. Treadwall, C. Young and J.C. Wynne, Evaluation of fatty acid components of forty peanut oil cultivars, Oleagineux 38 (1983) 381-388.

[2] M.H. Gordon, The development of oxidative rancidity, in: J. Pokorny, N. Yanishlieva, M. Gordon (Eds.), Antioxidants in Food - Practical Applications, CRC Press, Washington, (2001) pp. 7-22.

[3] E.N. Frankel, Oxidation of polyunsaturated lipids and its nutritional consequences. Oils-FatsLipids, in: Proceedings of the 21st World Congress of the ISF, Vol. 2, PJ Barnes and Associates, Bridgwater, (1996) pp. 265-269.

[4] F. Doleschall, Z. Kemény, K. Recseg, K. Kõvári, Monitoring of lipid degradation products by solid-phase microextraction. J. Microcolumn Separations, 13, (2001) 215-220.

[5] R.J. Hamilton, C. Kalu, E. Prisk, F.B. Padley, H. Pierce, Chemistry of free radicals in lipids. Food Chem., 60, (1997) 193-199.

[6] E.N. Frankel, Chemistry of autoxidation: mechanism, products and flavor significance. in: D.B, Min, T.H. Smouse (Eds.), Flavor Chemistry of Fats and Oils, AOCS, UrbanaChampaign, (1995) pp. 1-38.

[7] I. Medina, M.T. Satué-Gracia, E.N. Frankel, Static headspace gas chromatographic analyses to determine oxidation of fish muscle lipids during thermal processing. J. Am. Oil Chem. Soc., 76, (1999) 231-236.

[8] J. Pikul, Lipid oxidation and warmed-over flavour formation in heated and stored meat. Part II. Gosp. Miêsna, 8, (1992) 22-26.

[9] G. Pristouri, A. Badeka and M.G. Kontominas, Effect of packaging material headspace, oxygen and light transmission, temperature and storage time on quality characteristics of extra virgin olive oil, Food Control, 21 (2010) 412-418.

[10] A. Tsimis and N.G. Karakasides, How the choice of container affects olive oil quality- a review, Packaging Technology and Science, 15 (2002) 147-154.

[11] S. Dabbou, I. Gharbi, S. Dabbou, F. Brahmi, A. Nakbi and M. Hammami, Impact of packaging material and storage time on olive oil quality, African Journal of Biotechnology, 10(74) (2011) 16937-16947.

[12] M.A. Del Nobile, S. Bove, E. La Notte, and R. Sacchi, Influence of packaging geometry and material properties on the oxidation kinetics of bottled virgin olive oil, Journal of Food Engineering, 57 (2003) 189-197.

[13] A.K. Kiritsakis, and L.R. Dugan, Effect of selected storage conditions and packaging materials on olive oil quality, Journal of the American Oil Chemists' Society, 61 (1984) 18681870.

[14] M.R. Grover, Studies on shelf-life of vegetable oils packed in tin containers, Journal of Food Science and Technology, 19 (1982) 268-270.

[15] A. Mendez and E. Falque, Effect of storage time and container type on the quality of extravirgin olive oil, Food Control, 18(5) (2007) 521-529.

[16] F.M. Farhan and H. Pazandeh, Determination of traces of heavy metals in oils and fats by arc spectrography. J. American Oil Chemists Society, 53(5) (1976) 211-213.

[17] AOAC, Official Methods of Analysis of the Association of Official Analytical Chemist. Method Number 965.33b. AOAC Inc., Washington, US (1995).

[18] B. Halliwell and J.M.C. Gutteridge, Oxygen toxicity, oxygen radicals, transition metals and diseases, Biochemical Journal, 218, (1984) 1-14.

[19] D.A. Tsimis and N.G. Karakasides, How the choice of container affects olive oil quality, Packaging Technology and Science, 15 (2002) 147-154. 